\title{
Experiência estética do nadador. Um estudo a partir da perspectiva de atletas de natação de alto rendimento
}

\author{
Rita Fernandes \\ Teresa Lacerda
}

https://doi.org/10.5628/rpcd.10.01.180
Centro de Investigação, Formação,

Inovação e Intervenção em Desporto (CIFI2D)

Faculdade de Desporto

Universidade do Porto

Portugal

\section{RESUMO}

O presente estudo inscreve-se na estética do desporto, domínio que tem procurado contribuir para o entendimento dos aspectos relacionados com a sensibilidade e as emoções, sempre presentes e inseparáveis do desporto, num contexto de permanente crescimento e desenvolvimento deste fenómeno que integra a dinâmica cultural da contemporaneidade. O trabalho focalizou-se na caracterização da experiência estética do nadador de alto rendimento, cumprindo o propósito fundamental de produzir informação que se constituísse num contributo significativo para a compreensão dessa experiência.

Fez-se uso da metodologia qualitativa por meio da aplicação de uma entrevista semi-estruturada a 10 nadadores de elite (7 pertencentes à equipa olímpica de Portugal, Pequim 2008), tendo sido as narrativas discursivas submetidas a análise de conteúdo, da qual resultou um quadro categorial.

A análise da informação recolhida permitiu mapear os elementos que intervêm de modo significativo na experiência estética dos nadadores, designadamente: o corpo, a técnica, o sentir a água, a díade vitória-derrota e o contexto ambiental.

\author{
ABSTRACT \\ Aesthetic experience of the swimmer. \\ A study grounded in the perspective of elite swimmers
}

The current study fits in the field of the aesthetics of sport. This field aims to contribute to the understanding of aspects related to sensibility and emotions, always present and inseparable from sport, within a context of its continuous growth and development as a cultural phenomenon. The purpose of this paper was to describe the aesthetic experience the swimmer, aiming to contribute to a better understanding of the subject. Using a qualitative methodology, 10 high performance athletes ( 7 were part of the Portuguese Olympic team in Beijing, 2008) were interviewed following a semi-structured interview script. The contents of their narratives were then submitted to content analysis in order to reach an assemblage of categories that could explain the swimmers aesthetic experience. Those categories were: body, technique, feeling the water, victory versus defeat, and the surrounding environment.

Key-words: swimming, aesthetic experience, body, water 


\section{INTRODUÇÃO}

A estética do desporto vem-se afirmando como um domínio que contribui para um melhor entendimento do fenómeno desportivo, exaltando o seu valor e realçando-o como manifestação cultural(19). Remete para o conhecimento do sensível, do emotivo, do que de mais profundo existe no ser humano, aliando-se, ainda assim, à racionalidade.

Um contributo apreciável para o desenvolvimento desta temática tem surgido por meio das aproximações ao domínio da arte (argumentando-se a favor e contra a consideração do desporto neste âmbito), assim como por um certo esforço de categorização dos desportos de acordo com a importância relativa da estética na expressão da performance $(7,8,9,17,21,25$, 26, 30). O presente trabalho funda-se no pressuposto enunciado por diversos autores $(9,10,11,19,26,29)$ de que o desporto (e, consequentemente, a pluralidade dos desportos), pode ser considerado como um objecto estético que compreende qualidades estéticas latentes e que é passível de que acerca dele se emitam juízos estéticos (juízos de gosto).

Parece ser inegável que um dos elementos centrais do desporto é o corpo, que se constitui igualmente numa categoria nuclear da estética do desporto. Bento(6) sinaliza que o desporto funciona como um campo de criação do homem, responsável pela configuração de ossos, músculos e articulações, sem esquecer a consciência, a vontade e a sensibilidade. $\mathrm{O}$ mesmo autor realça o desporto como uma forma de regresso do homem ao seu corpo, com o desejo de intencionalizar a sua biografia, escrever nele marcas e registo de aculturação e socialização. Na verdade, o corpo desportivo promove uma personalidade e uma identidade entre a multiplicidade de corpos. É hoje possível, com algum conhecimento, identificar o corpo de um nadador, de um ginasta, de um halterofilista, porque cada um tem inscrito em si as marcas específicas do grupo no qual se "forma": "O desporto é plural para corresponder à diversidade dos corpos individuais."(6, p. 174). Numa direcção análoga Lacerda(19) refere ser clara uma estreita ligação entre a plástica do corpo humano nos diferentes movimentos desportivos e o morfótipo desse mesmo corpo, assim como Boxill(8) evidencia que o morfótipo desempenha um papel fundamental na apreensão e especialização técnica e, por consequência, na atracção estética.
No domínio científico, o primado da técnica é confirmado e apontado como determinante do rendimento individual(12). Também no contexto da estética a sua importância é basilar: Boxill(8) refere-se à técnica como factor potenciador da estética e da formação de um estilo individual, aprimorado pela vontade de vitória, sendo que Arnold(1) chama igualmente a atenção para a possibilidade que o domínio técnico encerra de aumentar a excelência e expressão individuais.

Wright( ${ }^{(31)}$ enfatiza as potencialidades da técnica como catalizador de respostas emocionais no observador, testemunhando a sua afinidade com a estética. As respostas emocionais ao desporto são, em boa parte, resultado da manifestação da técnica em performances que elevam o corpo ao lugar da concretização e o situam no patamar último da competição, a vitória. Kupfer(18) destaca que a vitória resulta da interacção humana entre equipas e entre adversários, sendo essa interacção propiciadora de atracção estética. Do mesmo modo, Platchias ${ }^{(26)}$ realça o prazer estético desencadeado pelo atingir o resultado desejado por meio de uma exibição que se consubstancia num padrão vitorioso que desperta emoções, vividas por todos e por cada um na sua forma mais elevada. $\mathrm{O}$ acesso à dimensão estética do desporto não se confina ao observador ou ao atleta, mas ambos podem aceder à experiência estética.

O presente estudo desenvolveu-se a partir da consideração do ponto de vista do atleta relativamente ao desporto, tratando-se, no caso vertente, do universo sensível e emocional do atleta de natação de alta competição. A natação é uma modalidade que detém qualidades estéticas próprias, que podem ser observadas e vividas pelo espectador, e às quais o nadador pode igualmente aceder, sendo conduzido para uma experiência estética.

A carreira desportiva de uma das autoras, aliada ao forte interesse de ambas pelo estudo da estética do desporto, constituíram os principais motivos para o desenvolvimento da investigação. Para a ex-atleta de natação, a vivência do corpo, do seu $e u$ desportivo, despertou-a para um território sensorial e emocional, a princípio subconsciente e irreflectido, mas a pouco e pouco cada vez mais presente e mais lúcido no seu percurso desportivo. À medida que conhecia mais piscinas, mais parecia que se envolvia com a sua estrutura, criando quase que laços afectivos com 
umas, rejeitando outras, valorizando águas, pistas, blocos de partida e as sensações e sentimentos experimentados. A preocupação com as linhas do corpo, com a definição dos músculos, o nadar sem ruído, o toque da água, o estar em unidade com ela, todos estes aspectos começaram a habitá-la de forma cada vez mais nítida e recorrente, manifestando-se a performance como o apontamento final de um longo, sofrido e prazeroso processo, vivido durante muitas horas, dias, meses. Já não bastava apenas nadar, mas nadar com estética, ter beleza a nadar, num belo corpo de nadadora, tirar gozo de nadar em belas piscinas, as quais se encontram mais equipadas e decoradas em campeonatos de alto nível. Nadar comprido, deslizar, estar em harmonia com a água, como se ela integrasse um pouco a solidez do corpo da nadadora, que se liquefazia (em certa medida) para dela participar, começaram a ser aspectos integrantes do seu mundo da natação, em paralelo com a importância crescente atribuída ao envolvimento ambiental em que decorria a prova. Todos estes aspectos passaram a representar "cenas" do quadro desportivo da atleta, da sua "pintura" da modalidade e do seu trânsito permanente entre "artista" e "obra". O corpo que nadava, que corporizava a performance era, simultaneamente, o corpo que fruía e que vigiava a sua estética. Foi-se compreendendo que a importância destes aspectos era partilhada por muitos nadadores. Compreendeu-se ainda que, neste processo, a observação do outro exerce também uma forte influência na vontade do atleta ser belo a nadar. Torna-se quase impossível ser indiferente ao estilo de certos nadadores como, por exemplo, o emblemático Michael Gross ${ }^{1}$, cuja alcunha nos media era $o$ albatroz, tanto pela amplitude $(213 \mathrm{~cm})$ e o planar da sua braçada de mariposa, como pela beleza dessa amplitude. De igual modo, é incontornável mencionar a delicadeza do estilo de Popov² e a facilidade do nado de Michael Phelps ${ }^{3}$.

Deste modo se entende que um atleta é actor e espectador: descobre no sentir e no observar o fascínio e a quase obsessão por que a sua técnica seja estética, o gozo que deriva dessa facilidade e o prazer, quase poético, que nasce da relação do corpo com a água e com o movimento. Estar na água e mover-se nela é algo de profundamente vivido, como tão bem descreve Christine Rodes:
"Pouco a pouco intervalo mais as golfadas de ar, descomprimo, tranquila, tenho a impressão feliz de ter o busto maior, de vaguear em pleno céu líquido. A água está morna...a ausência de peso provoca euforia...Sentada em parte alguma e sobre nada...Cada vez me sinto melhor no fundo da piscina. Já não me apetece sair, que pena ter de respirar [... ] a carícia da água é divertida, superficial e absorvente. A água liberta e cativa ao mesmo tempo porque nela tudo se move, mas tudo se move com ela [...] Assim, depende do seu próprio movimento. Pouco a pouco, ausento-me. A embriaguez absorve-me, um tudo-nada mórbida. Algo me diz que devia sair... A superfície, esse horizonte visivel, cede ao rosto escondido das coisas. O real é um espelho sem mácula."

(Christine Rodes, Pour La Dance, 1986 In: Folha de sala do espectáculo de dança "Waterproof" de Daniel Larrieu)

As concepções de diversos autores acerca do conceito de experiência estética em termos gerais $(5,24)$ e no contexto do desporto $(8,14)$, foram importantes para o estabelecimento do objectivo do estudo que consistiu em caracterizar a experiência estética do nadador de alto rendimento. Entende-se que a experiência estética do nadador se funda em sensações e emoções que decorrem do uso do corpo que encarna o desporto, ou seja, o corpo que nada.

Habitando um corpo centro(28), um corpo que nasce da relação eu-outro, o atleta torna-se e molda-se corpo para si, para o outro, para a prática e para o elemento água. $\mathrm{O}$ atleta, por estar dentro da performance ${ }^{(1)}$, cria e renova permanentemente o desenho de realizações excelentes e únicas, e formula juízos de gosto no que concerne à estética do seu movimento. Nesta criação, experiencia a água e o leque de possibilidades associadas à imersão do seu corpo nesse elemento, vive o espaço, a presença do público, as cores, os sons..., cedendo lugar à experiência estética.

\section{METODOLOGIA}

A explicitação do objecto de estudo foi efectuada tendo em conta um conjunto de problemáticas teóricas de enquadramento, que serviram de suporte ao desenvolvimento do trabalho empírico. A consideração desse quadro conceptual (a que se aludiu de forma breve na Introdução), permitiu a operacionalização dos conceitos emergentes da literatura que 
fundamentaram o trabalho de campo. Este foi orientado e enformado para a procura de esclarecimento de dimensões relacionadas com o universo sensível, emocional, comunicacional - estético - dos atletas. Deste modo, fez-se uso do método qualitativo por meio da aplicação de uma entrevista semi-estruturada, o que possibilitou a exploração de algumas vias passíveis de orientarem futuras investigações. Esta metodologia permitiu não apenas descrever a informação recolhida, mas também valorizar o significado atribuído pelos atletas 'aos diferentes aspectos inerentes à problemática em estudo e interpretar o seu sentido. Como assinalam Quivy e Campenhoudt(27), a vantagem associada a esta metodologia reside na possibilidade de recolher testemunhos e interpretações dos interlocutores, respeitando os seus quadros de referência, a sua linguagem e as categorias mentais. A análise da experiência estética resultante da percepção do objecto experimentado, vivido e sentido, nas dimensões subjacentes à prática desportiva da natação de alto rendimento, implicava entrar em linha de conta com os significados atribuídos pelos actores e a intensidade da sua dedicação e ligação à modalidade e seu universo envolvente.

O grupo de estudo integrou 10 nadadores de alta competição (5 homens e 5 mulheres), com percursos desportivos relevantes (entre os quais 7 nadadores olímpicos, Pequim 2008) e idades compreendidas entre os 19 e os 29 anos.

A informação recolhida através de uma entrevista semi-estruturada foi tratada por meio da técnica de análise de conteúdo. Optou-se por uma análise categorial temática para assim restituir o sentido do discurso dos entrevistados e tentar chegar ao conteúdo implícito da comunicação. Esta análise assentou nos postulados sugeridos por Bardin(3) para uma análise categorial, calculando e comparando frequências de certas características previamente agrupadas em categorias significativas. Fez-se uso ainda da contribuição da análise da avaliação para o registo dos diferentes juízos, bem como a sua direcção (como foi o caso do belo/feio, gosto/não gosto).

Neste sentido, as categorias foram definidas, integradas e formatadas no guião da entrevista segundo agrupamentos temáticos sugeridos pela literatura e de acordo com o objectivo da pesquisa. As respostas dos entrevistados foram analisadas mediante o enquadramento nas categorias pré-existentes, criando-se, igualmente, outras categorias que decorreram do processo analítico. No primeiro grupo integraramse as categorias corpo, técnica, vitória-derrota e contexto ambiental; no segundo, a categoria sentir a água.

\section{RESULTADOS}

Os resultados do estudo apresentam-se na presente secção. De forma a ilustrar e enriquecer a análise citam-se, regularmente, excertos dos discursos que melhor permitem conhecer a experiência estética dos nadadores, bem como a sua reflexividade sobre esta temática.

\section{Corpo do nadador}

As experiências individuais de cada um no e com o seu corpo deram a perceber a vivência de um corpo sensível, construído para a prática, através da preocupação pela estética da forma: "quanto mais fino, mais magro, forte mas magro tu fores, melhor para a dinâmica da água" (E4). Trata-se de um corpo que se apresenta num morfótipo ideal para a natação, que pretende ser portador de visibilidade estética por referência a padrões desportivos e que, simultaneamente, não recusa, mas antes parece ansiar, pela aproximação a estereótipos sociais: "somos sempre mais elegantes, um aspecto mais saudável, os músculos mais definidos (...) as pernas são mais bonitas do que as pernas das outras pessoas" (E8). Giddens(13) explica que os "(...) nossos corpos são profundamente afectados pelas nossas experiências sociais, bem como pelas normas e valores dos grupos aos quais pertencemos." Assistiu-se a um desdobrar de si em múltiplas visões decorrentes da multiplicidade das formas corporais destacadas (musculatura definida, magreza, ombros largos, membros superiores compridos), cada uma proveniente do modo como cada atleta vive, sente e comunica com o seu corpo, e resultante também do projecto (28) que cada um tem com ele: "O que eu mais gosto é de ter um tónus muscular, de ter forma e costas largas. Eu acho que até já cheguei a um ponto exagerado mas até acho bonito." (E4), ou, numa outra opinião: "tenho uns braços compridos e penso que me são bastante úteis" (E10). O corpo de nadador, na fala dos entrevistados, é um corpo que pretende transmitir um poder triplo que se consubstancia na força: i) que deriva do seu morfótipo; ii) com que domina o meio (água); iii) que 
representa para o outro. Assim, uns abordaram a questão do modo seguinte: "se estamos com alguma coisa fora do lugar, isso influencia na posição, na flutuação (...) pode ser uma questão de estética envolvida, pode ser feito fora de água, modelar o corpo fora de água para ele funcionar melhor dentro de água" (E4); outros reforçaram a vertente da plástica do movimento na autopercepção para o domínio do meio: "eu na água sintome maior (...) sinto-me grande a nadar (...) quando estou a nadar imagino o dobro daquilo que sou, porque sinto-me a nadar muito comprido, porque sinto que a minha braçada é forte, porque sinto que a minha ondulação é muito boa" (E9)"; outros ainda sublinharam a efectivação do seu poder sobre o adversário: "dentro de água quero é ganhar ao que está ao lado. E o que eu sinto é vontade de fazer melhor do que ele, vontade de conseguir fazer melhor do que aquilo que faço" (E5).

O poder transparece em gestos próprios de cada nadador, gestos singulares que parecem garantir individualidade pela forma como se manifestam em performances únicas e vitoriosas. O corpo estilizado pelas conveniências da prática(6) é a representação de um atleta, é a sua marca identitária na competição e só se torna possível pela forte consciência de si mesmo: "eu tenho uma estrutura um pouco pesada, então eu tenho que ter uma força a mais para carregar a minha estrutura" (E4). Na alta competição a consciência e a percepção de si são fundamentais na sensibilidade do corpo para a adequação ao gesto. Obter um elevado grau de sensações e percepções cinestésicas condiciona o desenvolvimento da coordenação das actividades motoras e facilita a correcção técnica favorecendo a percepção do gesto ideal(15) , conforme testemunharam os atletas: "eu tenho que me sentir a nadar bem e sinto as minhas provas (...) eu sabendo como é que hei-de fazer, consigo fazer com que o meu corpo faça aquilo" (E1).

\section{Técnica}

A capacidade de aprimorar um gesto é dada, para além das possibilidades decorrentes do morfótipo ideal, pela especialização técnica de cada um. A facilidade com que o corpo que realiza o movimento expressa a técnica, representa uma mais-valia estética, traduzindo-se quer em graciosidade e harmonia, quer numa melhor apropriação do corpo à água e a si mesmo: "é preciso uma técnica extremamente refinada para se conseguir deslocar com agilidade" (E4), ou ainda, como referiu outro entrevistado: "se tivermos uma técnica muito apurada, somos muito mais eficientes, o rendimento é muito superior" (E10). A eficiência técnica pode resultar em prazer estético, como afirmou o mesmo nadador: " $O$ que me dá prazer quando estou na água é ser eficiente, com o mínimo de esforço possível fazer o melhor tempo possível" (E10).

Enquanto observadores de natação especializados, os nadadores acedem à experiência estética também pela via da observação, sendo que a facilidade no desempenho técnico continua a ser valorizada em termos estéticos: "o que fica bem são aquelas técnicas em que a pessoa nada comprido e parece que não está a custar nada. É mesmo bonito de ver uma nadadora a nadar comprido" (E6).

Facilidade, eficiência, deslize, leveza, velocidade, amplitude, suavidade, flutuação e fluidez emergiram como os requisitos estético-técnicos valorizados pelos nadadores, não só porque são indutores de uma melhor adaptação ao meio, traduzindo-se em melhores resultados, mas também porque suscitam prazer estético e promovem mais e melhores sensações de nado, como explicou um dos entrevistados: "fazer de maneira a conseguir ganhar posições onde a pessoa sente que desliza mais (...) e sentir quando é que realmente se está a andar" (E2). Deste modo, o nadador rende-se à fruição do seu movimento: "é aquela sensação de leveza nas competições, de leveza e de estarmos a voar (entre aspas)" (E7). O nadador dá lugar à procura destas sensações, à perfeição do gesto e à melhor consciência de si, no sentido de garantir exibições vitoriosas mas, ao mesmo tempo, belas, em que a harmonia do corpo com a água e a ausência de ruído são uma preocupação constante e permanente: "haver alguma suavidade naquilo que se faz, apesar de transmitir muita força, a força não quer dizer que seja à bruta, pode ser forte mas de uma maneira suave, não estar a lutar com a água, estar a deslocar-se nela" (E8).

A técnica potencia a estética $(8,31)$ e a formação de um estilo individual. Ao ser autor e agente da sua performance $^{(1)}$, o atleta saboreia como recompensa a sensação e a emoção resultantes de um gesto excelente: "até nos treinos consegues dar muito mais a pensar na técnica e isso ao início custa mas no final é mesmo gratificante, porque estás a nadar bem, custa-te menos e nadas muito mais rápido" (E6). 


\section{Sentir a água}

$\mathrm{Na}$ adaptação da técnica ao corpo imerso no meio aquático, desenvolve-se um conceito comum: sentir a água. Este conceito remete para o universo sensível, emocional e comunicativo do nadador na relação que constrói entre si e o elemento água. Dessa relação de intimidade resulta um estado de fusão, que procura a harmonia com o elemento líquido e proporciona um prazer extremo que se inscreve no domínio estético. Com frequência, essa intimidade percebeu-se viva mas "mergulhada" no domínio do subconsciente, sendo à medida que os atletas falavam sobre ela que desenhavam e se tornavam conscientes desse envolvimento: "Sentir a água passar pelo nosso corpo, sentir a agarrar a água com as mãos, com o antebraço, com tudo aquilo (...) para nós a água faz tão parte da nossa vida de nadador que já nem pensamos" (E1). De facto, a experiência estética é muito recorrentemente irreflectida, talvez por ser algo de co-natural ao homem. No entanto, a familiaridade com a água, o at homeness ( $\mathrm{a}$ que alude Cordner(6) ) do corpo que nada, precipita para a experiência estética. Quando estamos submersos sentimos o corpo ser tocado por inteiro, e a água, por si só, desperta para a sensibilidade(2).

Por outro lado, nadar e estar na água desempenha um forte papel nas fantasias inconscientes ${ }^{(4)}$, sugerindo estados emocionais agradáveis e harmoniosos e despertando os sentidos (resultado do aumento da sensibilidade do nadador ao meio): "eu gosto de me sentir com a água (...) gosto de andar debaixo de água, gosto do barulho, da sensação de estar completamente submersa (...) de sentir a água a passar-me no corpo todo" (E9). Da imersão na água resulta um ampliar da sensibilidade que promove a fantasia e, em última instância, constitui a manifestação óbvia da simbiose eu-meio, na adaptação de um corpo à água pela consciência dos seus movimentos: "Sentir a água é como se fosse uma camisola que nos envolve toda, é como se estivéssemos dentro de um saco e depois tirassem o ar (...) o saco cola-se à pele (...) é como se estivéssemos aconchegados por alguma coisa que é a água." (E10). Esta forma de sentir é particularizada nos pormenores das descrições dos atletas: "sentem-se águas mais pesadas $e$ menos pesadas (...) não sei porquê, mas porque parece que quando puxamos, quando fazemos a braçada puxamos mais água, logo parece que a água é mais pesada” (E8).

Sentir a água parece provocar uma maior vivência de si, aumentando o universo sensorial das respostas à adaptação da técnica, promovendo mais emoções e permitindo experiências estéticas mais intensas. Vê-se aumentada a possibilidade da qualidade do movimento, da vitória e da estética, como é declarado por um dos nadadores:"eu só consigo nadar ao mais alto nível, ao meu nível, se me estiver a sentir bem dentro de água. Tenho de entrar na água da piscina e ter essa vontade de me sentir bem a nadar, de sentir a água, senti-la passar nas mãos, sentir...ter as sensações todas, senti-la nos pés, sentir a velocidade da água a percorrer o corpo...sentir isso" (E5).

\section{Vitória-derrota}

A vitória, ou o atingir o objectivo estabelecido, tornase a finalidade última de todas estas criações, sensações, emoções, transformações e adaptações. O corpo sensível experimenta-se em performances que podem ser vitoriosas ou não, consoante o objectivo a que cada nadador se tenha proposto, e desaguam no prazer estético desencadeado pelo atingir o resultado esperado(26). Nesta dimensão, e de acordo com a informação contida nas entrevistas, a experiência estética pode-se desenvolver: i) na experiência resultante das emoções e sensações que decorrem da vitória do atleta; ii) na experiência vivida pelo nadador com a resposta emocional que a sua prestação desencadeia nos outros; iii) na experiência decorrente das emoções e sensações que lhe são proporcionadas pelas vitórias dos outros, o que evidencia a importância da interacção humana, também ela propiciadora de atracção estética(18). Como mencionava um nadador: "o espectáculo da vitória, o festejar daqueles que ganham e o festejar, entre aspas, daqueles que perdem...essas emoções para mim trazem muita estética, são belas” (E9). A vitória e a derrota estão, portanto, implicadas na experiência estética, manifestando-se a fruição de cada uma delas por um estado emocional que conflui para uma multiplicidade de opiniões e formas de sentir e viver o momento. A propósito da vitória, foi referido por um nadador: "a sensação que mais me agrada é, realmente, aquela sensação de vencer (...) a sensação de felicidade depois" (E4), ou, como evidenciou outro atleta: "é uma sensação de prazer e de plenitude" E(8). A derrota apareceu para os entrevistados, como uma pretensa ponte para o aprimorar das capacidades e gestos do corpo, induzindo à procura interminável pela excelência e experimentando-se em estados 
emocionais de desilusão e frustração, por oposição à festa e à alegria da vitória: "quando nado mal...também relaxo... acabou a prova má...relaxo já para o lado da tristeza" (E4). Numa outra perspectiva, veiculada por outro nadador, a derrota pode traduzir-se num desafio renovado: "perceber o que correu mal (...) mas as derrotas são importantes quando conseguem gerar uma frustração que nos faz querer fazer mais e melhor" (E8). A derrota foi ainda perspectivada como uma possibilidade de fruição estética, na medida em que permite ao atleta rever-se como humano: "as derrotas a mim ensinam-me mais do que as vitórias" (E9). A capacidade de sobreviver às emoções derivadas da derrota, pode ser lida como um caracter distintivo dos atletas, como uma encenação do eu(6), conforme o discurso de um nadador: "admiro a personalidade e a maneira de ser do Popov... ele chegou a ser conhecido como um homem ice ... ele não festejava demais as vitórias e nas derrotas não ficava totalmente derrotado, parecia que aquilo até era uma derrota para ele mas que estava a aprender" (E5). A derrota pode, deste modo, abrir espaço à superação, como realçou um outro atleta: "Ainda continuo a competir porque vivo constantemente com o sentimento, com a sensação, de que consigo fazer melhor" (E10). Se a vitória constitui a expressão da excelência no desporto, a derrota pode assumir-se como uma via na procura dessa excelência, como um processo de aprendizagem que humaniza o resultado.

\section{Contexto ambietal}

Embora marginal à performance em si, o contexto ambiental em que decorre o treino e a competição desportiva é passível de exercer influência na experiência estética do nadador. Masterson(21) evidencia que a luz, a cor, o som, concorrem para a intensificação da estética do espectáculo desportivo.

O discurso dos entrevistados deu a perceber um conjunto de características influenciadoras da experiência estética que surgiu associado ao lugar no qual decorre a prática da natação, a piscina: dimensões, espaço, cores, luzes, público, equipamentos técnicos e temperatura, foram alguns aspectos enunciados como intervindo sensorial e emocionalmente no atleta, comunicando algo de significativo no que se refere à relação corpo/lugar. Estes factores funcionam como experiência fenomenológica(2), já que provocam um impacto no jogo das percepções e emoções.
Trata-se de uma percepção captada na experimentação dos objectos, cheirando, tocando, sentindo(24), como referia um dos entrevistados: "a água é uma coisa que eu gosto imenso de ver, a água assim azulinha ou límpida (...) e quando estão luzes associadas então é o que me fascina mais" (E8); um outro entrevistado mencionou: "para mim é a luz! Principalmente nas piscinas descobertas, eu gosto muito da luz (...) transmite-me muita força e muito mais alegria" (E8). Um outro ainda sublinhou: "gosto de olhar para os blocos, gosto de olhar para as pistas e se a piscina acaba lisa (caldeira finlandesa), rentinha, ou se tem paredes a delimitar... aquela ideia de continuidade para mim... eu gosto... eu gosto mais." (E2). Estas características parecem accionar diversos estados emocionais e promover a criatividade ao nível do modo como o nadador vê a sua prestação, enquadrada na relação que estabelece com o espaço, como é bem expresso no discurso que se segue, formulado a propósito de uma piscina onde o entrevistado nadou: "Era exactamente um anfiteatro onde nós entramos, os artistas. Tinha bancada a toda a volta, estava tudo negro $e$ as luzes apontavam para o palco, o palco era a piscina $e$ isso é o essencial (...) e a primeira vez que eu entrei na água senti que estava no palco e que estava a ensaiar (...) é o meu mundo aquilo, fico no meu mundo ao máximo"(E9). $\mathrm{O}$ espaço surge como potenciador das qualidades estéticas do momento desportivo, projectando um conjunto de estímulos que favorecem uma comunicação própria entre o atleta e o recinto desportivo, intensificando a qualidade da experiência estética: "eu gosto do sol directo numa piscina, isso dá-me uma energia, sinto-me muito bem num ambiente assim" (E4) ou, como referiu outro nadador: "gosto de sítios amplos, gosto de espaço, gosto de ter a sensação de liberdade" (E8) e ainda um outro, a propósito de uma piscina olímpica: "a de Atenas tinha umas bancadas, aquilo parecia um estádio de futebol mas sem relva no meio...era a piscina! E isso dá uma força enorme à piscina, gostei!” (E2).

\section{CONSIDERAÇÕES FINAIS}

O corpo sensível do nadador dissolve-se em si próprio, na água e nos demais elementos essenciais ao universo da natação, numa procura permanente da excelência do gesto e do movimento, na apropriação de um espaço que quer como seu. Esse corpo sente-se, vive-se e comunica-se intensamente, acedendo à experiência estética pelo desporto. A natação contém 
em si o potencial que desperta este conceito.

A experiência estética do atleta de natação funda-se, primeiramente, no corpo do nadador, pela sua forma, poder e consciência, que lhe permitem retirar sensações agradáveis ou desagradáveis da actividade que desenvolve.

A vivência estética propaga-se pelo impacto da técnica no corpo e no nado, desmembrando-se em facilidade, eficiência, deslize, leveza, velocidade, amplitude, prazer, suavidade, flutuação, fluidez.

Sentir a água representa uma categoria estética quase exclusiva da natação, originária na relação que se estabelece com e no elemento água. Neste desporto, corpo e água fundem-se num só, tornando-se o ambiente líquido agente promotor de uma dupla personalidade: a do indivíduo que vive em meio terrestre e a do nadador que vive no meio aquático.

A experiência estética decorre da emoção implicada pelo atingir o melhor resultado, expresso pela vitória, e convive também com a emoção da derrota, consubstanciando-se em estados emocionais multiformes.

A relação corpo/lugar, materializada no contexto ambiental em que ocorre o treino e a competição de natação, afigura-se como um cenário importante à estruturação da experiência estética. Os elementos constituintes do espaço (dimensões, luz, cores, sons), são incorporados pelo nadador, que lhes atribui sentido e significado emocional.

O presente estudo constituiu uma primeira aproximação à compreensão da experiência estética do nadador de alto rendimento. As particularidades inerentes ao facto de se tratar de um desporto que se desenvolve no meio líquido (locus original da vida humana, na sua dimensão intra-utrina), constituem um desafio suplementar à estética do desporto pelo que o caminho para futuras investigações está em aberto.
NOTAS

${ }^{1}$ Michael Gross. Ex-nadador Alemão. Entre 1981 e 1991 foi campeão olímpico; campeão do mundo; campeão da Europa e recordista mundial dos $100 \mathrm{~m}$ e $200 \mathrm{~m}$ mariposa e dos $200 \mathrm{~m}$ crol.

${ }^{2}$ Alexander Popov. Ex-nadador Russo. Entre 1990 e 2004 foi campeão olímpico; campeão do mundo; campeão da Europa; recordista mundial de 50 e $100 \mathrm{~m}$ crol.

${ }^{3}$ Michael Phelps. Nadador Norte-Americano. Entre 2000 e 2008

foi campeão olímpico; campeão do mundo; recordista olímpico e mundial em diversos estilos e distâncias; conquistou 8 medalhas de ouro num único evento olímpico, Pequim (2008).

\section{CORRESPONDÊNCIA}

Teresa Lacerda

Faculdade de Desporto

Rua Dr. Plácido Costa, 91

4200-450 Porto

Portugal

E-mail: tlacerda@fade.up.pt 


\section{REFERÊNCIAS}

1. Arnold PJ (1985). Aesthetic aspects of being in sport: The performer's perspective in contrast to that of the spectator. Journal of the Philosophy of Sport, 12 (1): 1-7

2. Bachelard G (1989). A Água e os Sonhos. São Paulo: Martins Fontes

3. Bardin L (1994). Análise de Conteúdo. Lisboa: Edições 70

4. Baker J (2005). Fears and fantasies of swimming and being in water. Psychodynamic Practice, 11(3): 311-324

5. Beardsley MC, Hospers J (1997). Estética. Madrid: Ediciones Cátedra, S.A.

6. Bento JO (2006). Corpo e Desporto: Reflexões em torno desta relação. In: Séc. XXI: A era do corpo activo. Campinas: Editora Papirus, 155-182

7. Best D (1988). The aesthetic in sport. In: W. J. M. K. V. Meier (ed.), Philosophic inquiry in sport. Champaign, Illinois: Human kinetics Publishers, Inc., 477-493.

8. Boxill JM (1985). Beauty, sport and gender. In: W. J. M. K. V. Meier (ed.), Philosophic inquiry in sport. Champaign, Illinois: Human kinetics Publishers, Inc., 509-518

9. Cordner C (2003). The meaning of graceful movement. Journal of the Philosophy of Sport, 30 (2): 132-143

10. Cunha e Silva P (1999). O Lugar do Corpo. Elementos para uma Cartografia Fractal. Lisboa: Instituto Piaget

11. Davis P (1999). Boxill's stylish ambiguity. Journal of the Philosophy of Sport, 26 (1): 88-94

12. Fernandes R, Vilas-Boas JP (2001). Partidas e viragens em natação: descrição e sequências metodológicas. Comunicação apresentada no II Seminário de Natação "Novos Horizontes". Viseu

13. Giddens A (2004). Sociologia (4 $4^{\mathrm{a}}$ ed.). Lisboa: Fundação Calouste Gulbenkian

14. Gumbrecht HU (2006). In Praise of Athletic Beauty. Londres: The Belknap of Harvard University Press

15. Kaluga E, Rostkowska E (2006). A Comparative analysis of changes in tactile sensitivity in men and women practicing selected sports. Human Movement, 7(2): 153-161

16. Kant I (1998 [1790]). Crítica da Faculdade do Juízo. Lousã: Imprensa Nacional-Casa da Moeda
17. Kuntz P (1985). Aesthetics applies to sports as well as to arts. In: D. L. Vanderwerken \& S. K. Wertz (eds.), Sport inside out. Fort Worth: Texas Christian University Press, 455-475

18. Kupfer J (1975). Purpose and beauty in sport. Journal of the Philosophy of Sport, 2(1): 83-90

19. Lacerda TO (2002). Elementos para a construção de uma Estética do Desporto. Porto: Teresa Oliveira Lacerda. Dissertação de Doutoramento apresentada à FCDEF-UP.

20. Machado I (2000). Corpo e espaço: Elementos para uma leitura do corpo performativo através das artes plásticas no século $X X$. Porto: Isabel Machado. Dissertação de Mestrado apresentada à FCDEF-UP.

21. Masterson D (1983). Sport, theatre and art in performance. In: H. Lenk (ed.). Topical problems of sport philosophy. Schorndorf: Verlag Karl Hofmann, 169-183.

22. Melo VA (2005). A presença do Esporte no Cinema: de Etienne-Jules a Leni Reifenstahl. Movimento, 11(2): 111-130

23. Merleau-Ponty M (2000). O Olho e o Espírito ( $3^{\mathrm{a}}$ ed.). Águeda-Lisboa: Vega

24. Mitias MH (1986). Can we Speak of "Aesthetic Experience?”. In: M. H. Mitias (ed.). Possibility of the Aesthetic Experience. Dordrecht: Martinus Nijhoff Publishers, 47-58

25. Parry J (1989). Sport, art and the aesthetics. Sport Science Review, 12: 15-20

26. Platchias D (2003). Sport is Art. European Journal of Sport Science, 3(4): 1-18

27. Quivy R, Campenhoudt L (1992). Manual de investigação em Ciências Sociais (1 ${ }^{a}$ ed.). Lisboa: Gradiva-Publicações, Lda

28. Sartre JP (1993 [1943]) O ser e o nada. Lisboa: Círculo de Leitores

29. Takács F (1989). Sport Aesthetics and its categories. Sport Science Review, 12: 27-32

30. Witt (1989). The world of sport - A world of aesthetic values. Sport Science Review, 12: 10-15

31. Wrigth L (2003). Aesthetic implicitness in sport and the role of aesthetic concepts. Journal of the Philosophy of Sport, 30(1): 83-92. 